\title{
Effect of copper and platinum intrauterine devices on endometrial morphology and implantation in the rabbit
}

\author{
J. A. Tobert* and D. R. Davies† \\ Department of Pharmacology, The School of Pharmacy, 29/39 Brunswick Square, \\ London WC1, and \\ † Department of Morbid Anatomy, St Thomas's Hospital Medical School, \\ London SEl, U.K.
}

\begin{abstract}
Summary. The response of the rabbit endometrium to the copper IUD was investigated. A plastic IUD bearing copper foil $\left(42 \mathrm{~mm}^{2}\right)$ was inserted into one horn of the rabbit uterus and a physically similar platinum-bearing IUD in the contralateral horn served as a control. The Pt-IUD caused no tissue damage and little if any inflammatory reaction in ovariectomized, oestrous or pregnant animals, whereas the Cu-IUD produced endometrial ulcers in 14 out of 15 does in all hormonal states. The associated inflammation was particularly intense in the pregnant animals in which a unilateral pyometra was usually present. Despite the endometrial trauma produced, the CU-IUD was only partly effective as a contraceptive agent, $36 \%$ of the ova shed from the ovary ipsilateral to the Cu-IUD implanting, compared with $63 \%$ of the ova ipsilateral to the Pt-IUD. However, almost half of the implantation swellings in the copper-bearing horns were abnormally small or distorted in shape at 9 days post coitum. The tissue destruction observed in the rabbit endometrium emphasizes the need for careful histological studies of the effect of the copper IUD on the human uterus.
\end{abstract}

\section{Introduction}

The copper intrauterine device is increasingly widely used because it appears to offer advantages over conventional devices in terms of less bleeding and pain and easier insertion (Tatum, 1973; Orlans, 1973). Furthermore, unlike the older plastic IUDs, it is well tolerated by nulliparae and might be an alternative to the oral contraceptive pill in these patients (Mishell, Israel \& Fried, 1973).

Copper is one of the more cytotoxic metals when implanted in various tissues, producing considerable necrosis and abscess formation (Fischer, Sayre \& Bickford, 1957; Wu, Dennis \& Sawyer, 1967; Duke-Elder \& MacFaul, 1972), and its effect on the endometrium therefore merits investigation. The few reports that have appeared on the reaction of the human endometrium to the device indicate a fairly mild inflammatory reaction (Hagenfeldt, Johannisson \& Brenner, 1972). However, the published data have mainly related to endometrial biopsies, which are estimated to sample less than $1 \%$ of the endometrial mass (Moyer \& Mishell, 1971), and thus tissue reactions highly localized to the copper may have been missed. Moreover, direct comparison with devices not bearing copper has not been made.

In this study, the reaction of rabbit endometrium in different hormonal states to the presence of a copper intrauterine device (Cu-IUD) has been examined and compared to the response to a physically similar device bearing the inert metal platinum (Pt-IUD), At the same time, observations were made on the influence of the devices on implantation, the dissolution rate of the copper, and the histochemical distribution of the dissolved metal. The rabbit was chosen because, like women, it responds to the presence of a plastic IUD with only a mild sterile inflammatory reaction (Ledger \& Bickley, 1966; Parr, Schaedler \& Hirsch, 1967) and because copper is reported to be effective as an intrauterine contraceptive agent in this species (Zipper, Medel \& Prager, 1969).

* Present address: Department of Clinical Pharmacology, Merck Sharp \& Dohme Research Laboratories, P.O. Box 2000, Rahway, New Jersey 07065, U.S.A. 


\section{Materials and Methods}

\section{Intrauterine devices}

The IUDs consisted essentially of a sleeve of metal foil on an acrylic rod (Pl. 1, Fig. 1). The advantages of the design are that (1) the devices bearing different metals are physically almost identical; (2) the use of foil instead of wire permits a simple adjustment of the mass: surface area ratios, and by using foils of different thickness a substantial fraction of the copper is dissolved within the period of the experiment, permitting accurate measurement of the copper loss; and (3) the metal sleeve on plastic resembles the devices used clinically - a plasticcarrier wound with close-spaced turns of wire or bearing copper sleeves.

Rectangular pieces $(6 \times 7 \mathrm{~mm})$ of $99.9 \%$ pure metal foil (Goodfellow Metals, Esher, England) 6.5 or $20 \mu \mathrm{m}(\mathrm{Cu})$ or $7.5 \mu \mathrm{m}(\mathrm{Pt})$ thick were affixed by means of an epoxy resin adhesive (Araldite, Ciba-Geigy, Summit, New Jersey, U.S.A.) in a shallow recession in an acrylic rod (Perspex: 1.C.I., Macclesfield, England) $21 \mathrm{~mm}$ long and $2.4 \mathrm{~mm}$ in diameter. The metals then formed a sleeve $6 \mathrm{~mm}$ long and the area of metal exposed was $42 \mathrm{~mm}^{2}$, terminating $1 \mathrm{~mm}$ from one end of the rod. A $4 / 0$ silk thread was passed through a hole in the other end of the rod and knotted. The security of the knot was ensured by a sleeve of medical grade silicone tubing (Silastic, Dow Corning, Midland, Michigan, U.S.A.) $10 \mathrm{~mm}$ long, i.d. $1.5 \mathrm{~mm}$, o.d. $2 \mathrm{~mm}$. The devices were disinfected before insertion by immersion in $\mathbf{0 . 2} \%$ chlorhexidine solution.

$\mathrm{Cu}-\mathrm{IUD}$ bearing the thicker $(20 \mu \mathrm{m})$ foil were used only for the oestrous rabbits to avoid perforation of the foil by the more corrosive uterine environment of the latter (Tobert, 1974).

\section{Animals}

Twenty-one virgin female New Zealand White rabbits weighing $3 \cdot 0-3 \cdot 9 \mathrm{~kg}$ were caged singly, kept in a 14 h daylight regimen, fed ad libitum and used when judged to be oestrous by the condition of the vulva.

Insertion of IUDs was performed through a midventral incision under pentobarbitone/halothane anaesthesia and aseptic conditions. A Cu-IUD was inserted into one horn (right and left alternating in successive experiments) and a Pt-IUD into the contralateral horn. The IUDs were introduced through a small antimesometrial incision, which was closed with a $4 / 0$ silk suture knotted with the IUD thread, thus fixing the IUDs in position with minimal mobility. The IUDs lay in the cervical third of the uterus and were orientated such that the metal-bearing end was the nearer to the uterotubal junction. Care was taken to ensure that both IUDs in each animal were equidistant from the cervix.

Three groups were established. In Group 1, no treatment was given to the 7 does. In Group 2, 3 does were bilaterally ovariectomized at the time of insertion of the IUDs. The 11 Group-3 does were mated twice 5 days after the insertion of the IUDs and given 50 i.u. HCG i.v. to ensure ovulation.

\section{Collection of specimens and implantation data}

At 14 days after insertion, the rabbits were again anaesthetized, and killed after removal of the uterus and inspection of the ovaries to exclude spontaneous pseudopregnancy in the oestrous animals and to count corpora lutea (CL) in the Group-3 rabbits. The number of CL was considered to be equivalent to the number of ova shed; no corrections were made for corpora lutea atretica or polyovuly but these effects are small and oppose each other (Adams, 1959). In the Group-3 does, the number, position, and average diameter of each implantation swelling was also noted. The swellings are approximately spherical at 9 days p.c. and the average diameter was taken to be the mean of two measurements at right angles.

After removal of the IUDs, the uteri were fixed in buffered formalin. Portions consisting of the tissue in contact with the metal, plus about $1 \mathrm{~cm}$ on either side, were embedded in paraffin wax, sectioned transversely in $2 \mathrm{~mm}$ steps at $4 \mu \mathrm{m}$, and stained with haematoxylin and eosin. The uteri of 2 does from each of Groups 1 and 3 were fixed in $70 \%$ ethanol containing $0.1 \%$ rubeanic acid to 
demonstrate copper by the method of Uzman (1956). The copper-stained sections were not used to assess uterine morphology, and neither were specimens from two mated rabbits which failed to conceive. The morphological results are based on examination of 30 specimens, i.e. both uterine horns of all the remaining animals, 3 ovariectomized, 5 oestrous and 7 pregnant.

\section{Determination of copper loss}

Copper lost from the IUDs was estimated spectrophotometrically (Woelfel, 1948) as previously described (Tobert, 1974).

\section{Statistical analysis}

Tests of significance were carried out as described by Siegel (1956).

\section{Results}

Two of the 11 animals in Group 3 failed to conceive and were excluded from calculation of the antifertility effects of the IUDs and histological examination.

In Group 3, a pyometra was evident at gross inspection in 8 of the 11 horns containing the Cu-IUD but in only 1 of the 11 platinum-bearing horns $(P<0.01$, Fisher Exact Probability test). In most cases the pus was confined to the length of uterus occupied by the IUD. Pus was not apparent to the naked eye in the animals in Groups 1 and 2.

\section{Endometrial morphology}

Platinum-bearing horns. Some leucocytes were present in the epithelium and stroma in all hormonal states (P1. 1, Fig. 2) but their numbers did not significantly exceed those found in normal animals. In the ovariectomized (Group 2) animals lymphocytes were present and in the other two groups there were a few neutrophil and eosinophil polymorphonuclear leucocytes. The features of the glands and stroma (Pl. 1, Figs 2 and 4) were similar to those described by Davies \& Hoffman (1973) for rabbits of different hormonal states.

Copper-bearing horns. In all specimens except one (in Group 2) the endometrium was ulcerated (PI. 1, Figs 3, 5 and 6). The stroma was oedematous and there was an infiltrate of leucocytes, mainly neutrophils, eosinophils and lymphocytes, which was particularly intense in the pregnant animals. Occasional multinucleate epithelial cells were found adjacent to the ulcers in Groups 1 and 2, as well as in the mated animals in which they occur normally (Davies \& Hoffman, 1973). In the Group 3 animals perivascular decidualization was noted in 5 of the 7 horns. Sections taken $3 \mathrm{~cm}$ from the device in the direction of the uterotubal junction in 2 does appeared normal.

Copper was visualized as greenish-black granules by rubeanic acid in the two pregnant animals but not in the two oestrous rabbits, and control specimens from the contralateral Pt-IUD-bearing horn were unstained. The granules were present mainly in the debris in the uterine lumen but were occasionally seen in epithelial cells.

\section{Implantation}

The numbers of implantation sites and the distance of the nearest site from the IUD are shown in Table 1. Implantation did not occur between the ovarian end of the device and the cervix. The Cu-IUD exerted a significantly greater antifertility effect than the Pt-IUD, $36 \%$ of the ova shed from the ovary ipsilateral to the $\mathrm{Cu}$ horns implanting compared with $63 \%$ for the $\mathrm{Pt}$ horns $\left(P<0.001, \chi^{2}\right.$ test with Yates' correction). Moreover, 2 of the 16 implantation swellings in the $\mathrm{Cu}$ horns were of abnormal shape and a further 5 had an average diameter of $\leqslant 7.5 \mathrm{~mm}$. The swellings in the Pt-IUD horn had a mean \pm S.E.M. diameter of $12.1 \pm 1.77 \mathrm{~mm}$ (range $8.5-17 \mathrm{~mm}$ ), values similar to those reported for normal rabbits (Adams, 1959). Of the 45 ova shed from the ovary ipsilateral to the Cu-IUD horns, therefore, $29(64 \%)$ failed to implant, $7(16 \%)$ resulted in abnormal implantations, and only $9(20 \%)$ gave rise to apparently normal implantations. 
Table 1. The effect of copper and platinum IUDs on implantation in rabbits

\begin{tabular}{|c|c|c|c|c|c|c|}
\hline \multirow[b]{2}{*}{ Rabbit } & \multicolumn{3}{|c|}{ Copper-bearing horn } & \multicolumn{3}{|c|}{ Platinum-bearing horn } \\
\hline & Implantations & $\mathrm{CL}$ & $Y$ & Implantations & CL & $Y$ \\
\hline A & $2(2)$ & 2 & 16 & 5 & 7 & 8 \\
\hline B & $3 t$ & 3 & 38 & 4 & 9 & 13 \\
\hline C & 0 & 5 & - & 2 & 5 & 17 \\
\hline D & 3 & 6 & 21 & 4 & 4 & 6 \\
\hline E & 0 & 6 & - & 1 & 2 & 20 \\
\hline $\mathbf{F}$ & 0 & 7 & - & 5 & 6 & 13 \\
\hline G & $2(1)$ & 6 & 42 & 5 & 7 & 13 \\
\hline $\mathrm{H}$ & 2 (1) & 4 & 70 & 7 & 7 & 0 \\
\hline I & $4(1)$ & 6 & 22 & $\mathbf{0}$ & 5 & - \\
\hline Totals & 16 & 45 & & 33 & 52 & \\
\hline Mean $Y$ & & & $35^{*}$ & & & $11^{*}$ \\
\hline
\end{tabular}

$Y$ represents the distance in $\mathrm{mm}$ between the ovarian (proximal) end of the device and the centre of the nearest implantation site.

Figures in parentheses refer to abnormally small implantations $(\leqslant 7.5 \mathrm{~mm}$ in diam.).

$* P<0.001$ by Mann-Whitney $U$ test.

$\uparrow 2$ of the 3 implantations were of abnormal shape.

\section{Copper loss}

The mean \pm S.E.M. copper loss from the devices during the 14 days in situ was $1105 \pm 105 \mu \mathrm{g}$ $(\mathrm{N}=7$ ) in Group 1, $910 \pm 58 \mu \mathrm{g}$ in Group 3 (pregnant animals only, $\mathrm{N}=9$ ) and $796 \pm 119 \mu \mathrm{g}(\mathrm{N}=3$ ) in Group 2. These differences are not statistically significant (Student's $t$ test, $P>0.05$ ). The variation in copper losses with different hormonal states (Tobert, 1974) would have been obscured in the present study by the fact that the animals in Group 3 were oestrous for the first 5 days of the experiment.

\section{Discussion}

The minimal inflammatory reaction to the Pt-IUD accords with the results of previous investigators using plastic tubing (Ledger \& Bickley, 1966; Parr et al., 1967). However, the ulceration and intense inflammation produced by the Cu-IUD have not been reported by other investigators for rabbits, although Nutting \& Mueller (1975), using an IUD bearing a much larger copper surface $\left(200 \mathrm{~mm}^{2}\right)$, noted epithelial erosions and isolated areas of focal necrosis. Zipper et al. (1969) and Johnson (1972) reported a normal endometrium, apart from stromal hypertrophy, in the presence of a copper wire, although Johnson found pus in the lumen. Abraham, Mankes, Fulfs, Goldberg \& Coulston (1974) noted epithelial sloughing but no significant leucocytic infiltration of the stroma. The surface area of copper in our devices, $42 \mathrm{~mm}^{2}$, is slightly greater than that of the devices ( 4 wires, $15 \mathrm{~mm} \times 0.15 \mathrm{~mm}$ giving a total of $28 \mathrm{~mm}^{2}$ ) used by Zipper et al. (1969) and Abraham et al. (1974), and less than that (about $130 \mathrm{~mm}^{2}$ ) used by Johnson (1972). However, the ratio of surface area of copper to the length of uterus it occupies is probably a more meaningful comparison. This ratio is $7.0 \mathrm{~mm}^{2} / \mathrm{mm}$ for our devices, $1.9 \mathrm{~mm}^{2}$ for those of Zipper et al. and Abraham et al., and about $2.2 \mathrm{~mm}^{2} / \mathrm{mm}$ for that used by Johnson. It seems possible, therefore, that in our animals the dissolved copper would initially be concentrated in a much smaller length of uterus, enabling cytotoxic concentrations to be reached adjacent to the metal.

The slight response to the Pt-IUD indicates that the reaction to the copper is due to the chemical, rather than the physical, nature of the Cu-IUD. It is probably caused by copper ions released from the device, because low concentrations of cupric ions are detrimental to cultures of human cervical epithelial cells (Hounsell \& Hawkins, 1974) and other cell types (Mauersborger \& Zorn, 1967), although other products of the reaction between the metal and uterine fluid could be responsible (Oster, 1972; Oster \& Oster, 1974). Copper in the high concentrations that occur in the liver in 

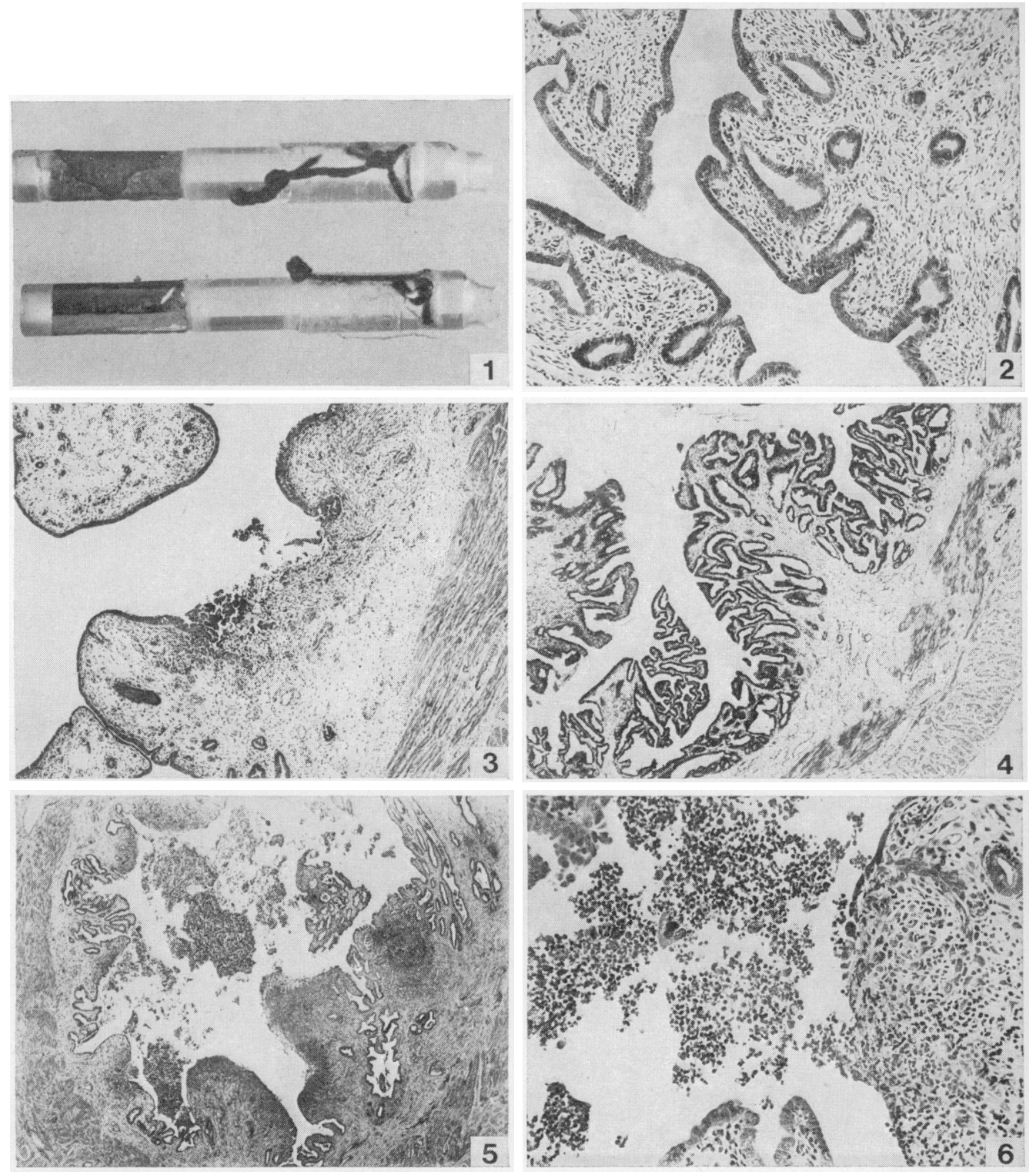

Fig. 1. Copper (above) and platinum devices after removal from the rabbit uterus. The copper sleeve is greatly corroded. $\times 3$.

Fig. 2. Section of the endometrium of an oestrous rabbit. The horn contained a platinum device, and the endometrium appears normal with scanty leucocytes. H \& E, $\times 75$.

Fig. 3. In the uterine horn of an oestrous rabbit containing a copper device, the endometrium is ulcerated with local oedema and inflammatory cell infiltration. $\mathrm{H} \& \mathrm{E}, \times 30$.

Fig. 4. The glandular appearance of the endometrium of a mated rabbit from the horn which contained a platinum device for 9 days post coitum is normal. $\mathrm{H} \& \mathrm{E}, \times 30$.

Figs 5 and 6. When a copper device was present in the uterus of a mated rabbit $(G)$ the endometrium was extensively ulcerated with oedema and inflamm atory cell infiltration. The lumen contains pus. H \& E, Fig. 5, $\times 25$; Fig. $6, \times 90$. 
Wilson's disease (hepatolenticular degeneration) causes cell death (Goldfischer \& Sternlieb, 1968). The demonstration of copper in the endometrial epithelium of the pregnant rabbit confirms the observation of Abraham et al. (1974) and indicates a copper level in this tissue considerably higher than normal. The tissue destruction observed in our animals is therefore not unexpected.

The response of the rabbit uterus to metallic copper is by no means unique (cat brain: Fischer et al., 1957; rabbit muscle: Wu et al., 1967; human eye: Duke-Elder \& MacFaul, 1972), but the mechanism of copper toxicity is unknown (see review by Bremner, 1974). The metal is taken up into lysosomes (Goldfischer \& Sternlieb, 1968) and one view is that the tissue damage is at least partly due to release of lysosomal enzymes (Lindquist, 1968; Abraham et al., 1974; Bremner, 1974).

The pyometra and more intense inflammation in the $\mathrm{Cu}$-bearing horns of the pregnant animals compared with those in the oestrous does was not due to a faster dissolution of copper because less copper was lost from the Cu-IUDs in Group 3 than in Group-1 animals. The pyometra cannot be attributed to bacterial infection (see Haynes, 1967) because (1) the devices were inserted under aseptic conditions; (2) the pyometra was confined to the $\mathrm{Cu}$-IUD-bearing horn; and (3) aerobic and anaerobic cultures on blood agar of pus from pseudopregnant rabbits bearing $\mathrm{Cu}$-IUDs have proved negative (Tobert, 1975).

The small antifertility effect of the platinum device accords with the findings of previous investigators (Ledger, Virkar \& Irvin, 1966; Parr et al., 1967; Zipper et al., 1969) who placed relatively inert materials near the rabbit cervix. The antifertility effect of $\mathrm{Cu}$ in the rabbit was reported by Zipper et al. (1969) and Polidoro, Culver, Thomas \& Hahn (1974). However, both groups observed a complete absence of implantation sites, whereas we found that 5 of our 9 rabbits had one or more apparently normal embryos in the horn containing the Cu-IUD. The reason for this difference is unknown, but cannot be attributed to the area of copper used or the degree of epithelial damage.

It is thought that the primary mechanism of action of the Cu-IUD is its ovotoxic effect (Webb, 1973; Abraham et al., 1974), perhaps a direct toxic effect of copper ions or an indirect effect due to intraluminal pus, or both. On this basis, in our study the pyometra produced by the copper would alone seem more than adequate to account for the antifertility effect observed, and there is no need to postulate any more subtle action on the endometrium (Segal \& Atkinson, 1973), although such an action cannot be ruled out.

Like that of the rabbit, the rat uterus responds to the presence of copper with an intense exudation of leucocytes (Cuadros \& Hirsch, 1972). The primate uterus seems to be relatively immune to the toxic effects of $\mathrm{Cu}$ : the rhesus monkey is reported to be unaffected by the presence of a Cu-IUD in the uterus, although the same $\mathrm{Cu}-\mathrm{IUD}$ placed in the peritoneal cavity elicited abscess formation (Moo-Young, Tatum, Brinson \& Hood, 1973). The effect of the device on human endometrial morphology has not yet been studied on a large scale. Such reports as have appeared (Zipper, Tatum, Medel, Pastene \& Rivera, 1971; Hagenfeldt et al., 1972; Salaverry, Mendez, Del, Zipper \& Medel, 1973) have been based on endometrial biopsies and do not indicate, in most patients, the gross pathology we have observed in rabbits, although leucocytic infiltration is usually present. Although the data are not strictly comparable, there is some evidence that copper is corroded faster by the rabbit uterus (Tobert, 1974) than by the monkey (Moo-Young \& Tatum, 1974) or human uterus (Hagenfeldt, 1972). Also, the periodic sloughing of the primate endometrium no doubt mitigates against a deepseated endometritis.

Despite these factors, the risk of toxic effects in the human uterus should not be ignored, particularly if increasing the surface area of copper in an effort to reduce pregnancy rates (Roy, Cooper \& Mishell, 1974) is a continuing trend. Further studies on the response of the human uterus to the copper IUD, with special attention to the luteal phase of the cycle, and comparison with inert devices, would seem to be indicated. Even if the human endometrium is shown to tolerate copper well, IUDs on occasion come to lie in contact with other tissues, such as the cervical canal or pelvic viscera, and these may be less resistant.

We are grateful for the skilled technical assistance provided by $\mathrm{Mr} \mathrm{D}$. Turvey, Mr A. E. Clark, Miss R. A. Hearn and Mr G. S. Crouch. 


\section{References}

Abraham, R., Mankes, R., Fulfs, J., Goldberg, L. \& Coulston, F. (1974) Effects of intrauterine copper wire on blastocyst and uterine lysosomes of the rabbit: a cytochemical and ultrastructural study. J. Reprod. Fert. 36, 59-67.

ADAMs, C.E. (1959) Studies on prenatal mortality in the rabbit, Oryctolagus cuniculus: the amount and distribution of loss before and after implantation. J. Endocr. 19, 325-344.

Bremner, I. (1974) Heavy metal toxicities. Q. Rev. Biophys. 7, 75-124.

Cuadros, A. \& Hirsch, A.G. (1972) Copper on intrauterine devices stimulates leucocyte exudation. Science, N.Y. 175, 175-176.

Davies, J. \& Hoffman, L.H. (1973) Studies on the progestational endometrium of the rabbit. I. Light microscopy, day 0 to day 13 of gonadotrophin induced pseudopregnancy. Am.J. Anat. 137, 423-446.

Duke-Elder, S. \& MacFaul, P.A. (1972) Mechanical injuries. In System of Ophthalmology, Vol. 14, part 1, pp. 461, 512, 661 . Ed. S. Duke-Elder. Henry Kimpton, London.

Fischer, G., SAYre, G.P. \& Bickford, R.G. (1957) Histologic changes in the cat's brain after introduction of metallic and plastic coated wire in electroencephalography. Proc. Staff Meetings Mayo Clinic $32,14-22$.

Goldfischer, S. \& Sternlieb, I. (1968) Changes in the distribution of hepatic copper in relation to the progression of Wilson's disease (hepatolenticular degeneration). Am. J. Path. 53, 883-901.

HAGENFELDT, K. (1972) Intrauterine contraception with the copper-T device. 1 . Effect on trace elements in the endometrium, cervical mucus and plasma. Contraception 6, 37-54.

HAgenfeldT, K., Johannisson, E. \& BRENNER, P. (1972) Intrauterine contraception with the copper-T device. 3. Effect upon endometrial morphology. Contraception 6, 207-218.

HAYNES, N. B. (1967) The influence of the uterine environment on the phagocytosis of spermatozoa. In Reproduction in the Female Mammal, pp. 500-511. Eds G. E. Lamming \& E. C. Amoroso. Butterworths, London.

Hounsell, P.G. \& Hawkins, D.F. (1974) Effect of copper on growth of human cervical epithelial cells in tissue culture. J. Obstet. Gynaec. Br. Commonw. 82, 712-718.

Johnson, M.H. (1972) The protein composition of secretions from pregnant and pseudopregnant rabbit uteri with and without a copper intrauterine device. Fert. Steril. 23, 123-130.

Ledger, W.J. \& Bickley, J.E. (1966) The effect of a plastic foreign body on the genital tract of the female rabbit: a gross and histologic study. Obstet. Gynec., N.Y. 27, 658-664.

LEDGeR, W.J., ViRKAR, K.D. \& IRVIN, L.A. (1966) Effect of a plastic intrauterine device upon implantation in the rabbit. Obstet. Gynec., N.Y. 28, 521-525.

LINDQUIST, R.R. (1968) Studies on the pathogenesis of hepatolenticular degeneration. III. The effect of copper on rat liver lysosomes. Am. J. Path. 53, 9031023.

MaUersborger, B. \& ZoRN, C. (1967) The effect of $\mathrm{CuSO}_{4}$ on the growth of mammalian cell cultures. Expl Cell Res. 48, 688-690.

Mishell, D.R., IsRael, R. \& Fried, N. (1973) A study of the copper $\mathrm{T}$ intrauterine contraceptive device in nulliparous women. Am. J. Obstet. Gynec. 116, 10921096.

Moo-Young, A.J. \& Tatum, H.J. (1974) Copper levels in maternal and fetal tissues of rabbits bearing intrauterine copper wires. Contraception 9, 487-496.

Moo-Young, A.J., Tatum, H.J., Brinson, A.O. \& Hood, W. (1973) Copper levels in tissues of rhesus monkeys bearing intrauterine or intra-abdominal copper devices. Fert. Steril. 24, 848-853.

MOYER, D.L. \& MishelL, D.R., JR (1971) Reactions of human endometrium to the intrauterine foreign body. II. Long term effects on the endometrial histology and cytology. Am. J. Obstet. Gynec. 111, 66-80.

Nutting, E.F. \& Mueller, M.R. (1975) The effect of a copper intrauterine device on the uterine histology and progestational response in pregnant and immature rabbits. Fert. Steril. 26, 845-856.

OrLANS, F.B. (1973) Copper IUDs-performance to date. Population Report, Series B, No. 1, 1-20.

OSTER, G. \& OsTER, G.K. (1974) Free radical production by metallic copper. Contraception 10, 273-280.

OsteR, G.K. (1972) Chemical reaction to the copper intrauterine device. Fert. Steril. 23, 18-23.

Parr, E.L., Schaedler, R.W. \& Hirsch, J.G. (1967) The relationship of polymorphonuclear leucocytes to infertility in uteri containing foreign bodies. J. exp. Med. 126, 523-538.

Polidoro, J.P., CUlver, R.M., Thomas, S. \& Hahn, D.W. (1974) Mechanism of anti-implantation by copper IUD in the rabbit: transport and recovery of ova. Contraception 10, 481-490.

RoY, S., COOPER, D. \& Mishell, D.R., JR (1974) Experience with three different models of the Copper $T$ intrauterine contraceptive device in nulliparous women. Am. J. Obstet. Gynec. 119, 414-417.

Salaverry, G., Mendez, M. Del C., Zipper, J. \& Medel, M. (1973) Copper determination and localization in different morphologic components of human endometrium during the menstrual cycle in copper intrauterine contraceptive device wearers. Am. J. Obstet. Gynec. 115, 163-168.

SEGAL, S.J. \& AtKInson, L.E. (1973) Mechanism of action of intrauterine foreign bodies. In Handbook of Physiology, Section 7, Endocrinology, Vol. 2, part 2, pp. 359-366. Eds R. O. Greep \& S. Geiger. American Physiological Society, Baltimore.

Siegel, S. (1956) Nonparametric Statistics for the Behavioural Sciences. McGraw-Hill, New York.

TATUM, H.J. (1973) Metallic copper as an intrauterine contraceptive agent. Am. J. Obstet. Gynec. 117, 602618.

TOBERT, J.A. (1974) The effect of hormonal state on the dissolution of copper in the rabbit uterus. Contraception 10, 203-210. 
TOBERT, J.A. (1975) Induction of deciduomata by intrauterine copper in the rabbit. J. Reprod. Fert. 45, 197200.

UZMAN, L.L. (1956) Histochemical localization of copper with rubeanic acid. Lab. Invest. 5, 299-305.

WEBB, F.T.G. (1973) The contraceptive action of the copper IUD in the rat. J. Reprod. Fert. 32, 429-439.

WOELFEL, W.C. (1948) Colorimetric determination of copper with carbon disulphide and diethanolamine. Analyt. Chem. 20, 722-725.
WU, K.T., DENNIS, C. \& SAWYER, P.N. (1967) The use of various metals to increase tensile strength of wounds. Surgery 61, 242-247.

ZIPPER, J., MEDel, M. \& PRAGER, R. (1969) Suppression of fertility by intrauterine copper and zinc in rabbits. Am. J. Obstet. Gynec. 105, 529-534.

ZipPer, J.A., TATUM, H.J., Medel, M., PAstene, L. \& RIVERA, M. (1971) Contraception through the use of intrauterine metals. I. Copper as an adjunct to the "T" device. Am. J. Obstet. Gynec. 109, 771-774.

Received 10 August 1976 